\title{
A Girl with Turner Syndrome with Hyperthyroidism during Growth Hormone Therapy
}

Hirohiko Higashino, Naoyuki Kitamura, Sawa Cho and Yohnosuke Kobayashi

Department of Pediatrics, Kansai Medical University, Osaka, Japan

Key words: Turner syndrome, hyperthyroidism, rhGH therapy

\section{Patient Report}

A twelve year old Japanese girl with Turner syndrome was treated with recombinant human growth hormone (rhGH) at a dose of $0.5 \mathrm{U} / \mathrm{kg} / \mathrm{wk}$. She developed goiter and mild exophthalmos at 13 years and 7 months of age. Methimazole was started for hyperthyroidism at a dose of $15 \mathrm{mg} /$ day. She developed breast budding at the age of 14 years and scant spontaneous vaginal bleeding at the age of 14 years and 8 months, but there was no further progression of breast development. Height velocity (HV) of the first 6 months was 6.8 $\mathrm{cm} / \mathrm{yr}$, and it waned thereafter down to 6 $\mathrm{cm} / \mathrm{yr}$. HV during the active period of hyperthyroidism and before vaginal bleeding were 5.4 and $6.6 \mathrm{~cm} / \mathrm{yr}$, respectively. There was a marked increase of alkaline phosphatase (ALP) level during the hyperthyroid period and it decreased after hyperthyroidism subsided(Fig. 1, 2). Height standard deviation score(SDS) for chronological age using the Turner references increased from -1.35 to +0.91 SDS.

Correspondence: Dr. Hirohiko Higashino, Department of Pediatrics, Kansai Medical University, 10-15 Fumizonocho, Moriguchi-shi, Osaka 570 Japan

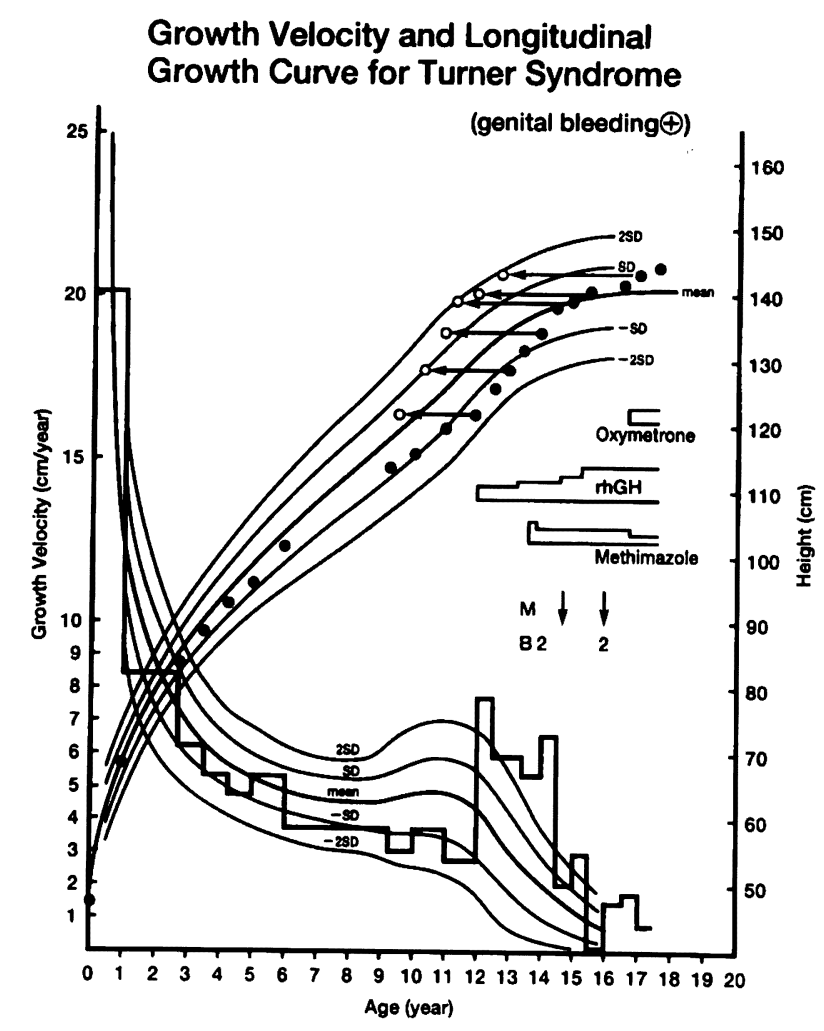

Fig. 1 Growth curve of the patient

(๑); chronological age, ( $\bigcirc$ ); bone age, B; breast, M; menstruation

\section{Discussion}

Massa(1) reported a patient with Turner syndrome whose $\mathrm{HV}$ was accelerated during hyperthyroidism and spontaneous puberty. Final height, however, was not influenced by 


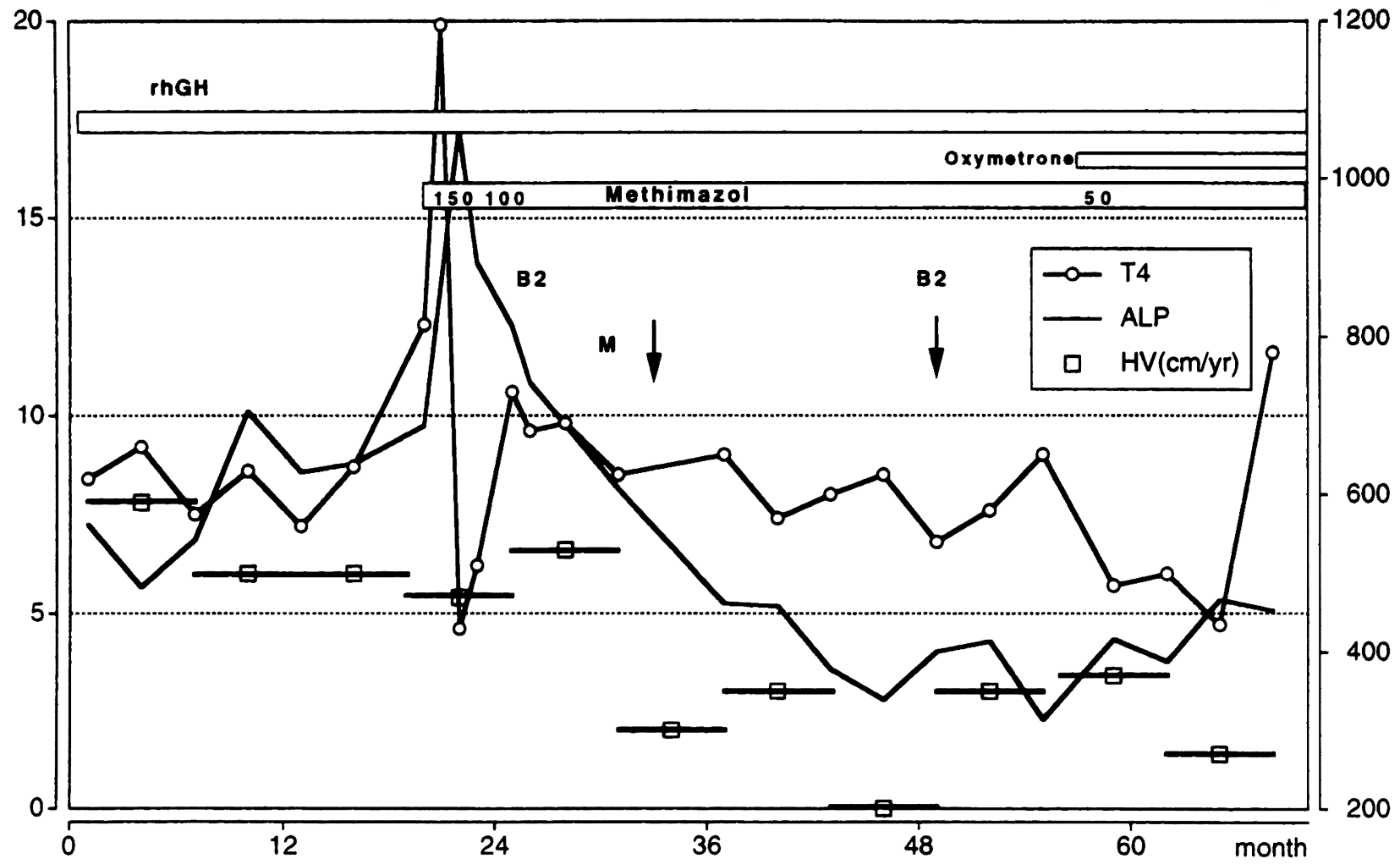

Fig. 2 Changes of T4, ALP, and HV during the treatment with rhGH and methimazol.

either hyperthyroidism or spontaneous puberty. In our patient, $\mathrm{HV}$ during hyperthyroidism did not increase, even though the serum ALP level was markedly elevated. This increment of serum ALP may reflect the stimulation of bone metabolism by thyroid hormone (2). After hyperthyroidism subsided, she developed incomplete spontaneous puberty and $\mathrm{HV}$ was accelerated during puberty but very little, probably because her growth rate had been already accelerated by the rhGH therapy before the onset of hyperthyroidism and the puberty period. There is not sufficient evidence as to whether this increment was due to the effect of thyroid hormone or sex steroids. It is impor- tant to observe changes of thyroid function as well as other growth parameters in patients with Turner syndrome treated with rhGH.

\section{References}

1. Massa G, Zegher F, Doom L, Vanderschueren-Lodeweyckx M. Hyperthyroidism accelerates growth in Turner's syndrome. Acta Paediatr 1992; 81: 362-4.

2. Warner MB, Van Wyk JJ. Triiodothyronine stimulates cartilage growth and maturation by different mechanisms. Am J Physiol 1987; 252(Endocrinol Metab 15): E176-82. 